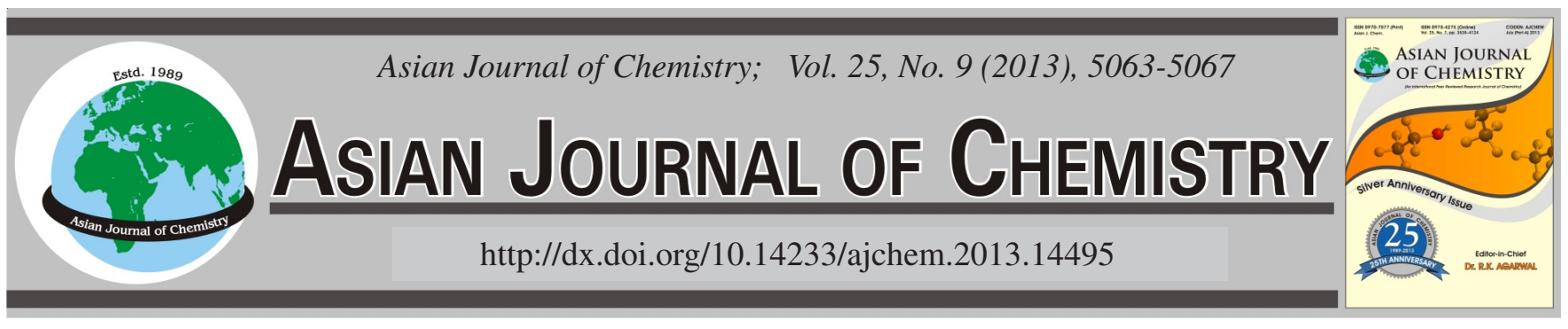

\title{
Preparation of Graphene-ZnO Nanocomposites under Electric Furnace and Photocatalytic Degradation of Various Organic Dyes
}

\author{
Bum Hwi $\mathrm{ChO}^{1}$, Seung Won $\mathrm{Ko}^{2}$, Won-Chun $\mathrm{OH}^{3}$ and Weon Bae $\mathrm{Ko}^{1, *}$
}

${ }^{1}$ Department of Chemisty, Sahmyook University, Seoul 139-742, South Korea

${ }^{2}$ Science Focus School, Incheon Sangok High School, Wonjeokro 416-25, Bupyung Ku, Incheon 403-011, South Korea

${ }^{3}$ Department of Advanced Materials \& Science Engineering, Hanseo University, Chungnam 356-820, South Korea

*Corresponding author: Fax: +82 2 9795318; Tel: +82 2 33991700; E-mail: kowb@syu.ac.kr; kowbsahmyook@syu.ac.kr

(Received: 28 August 2012;

Accepted: 20 March 2013)

AJC-13138

\begin{abstract}
The $\mathrm{ZnO}$ nanoparticles were synthesized by the reaction of an aqueous-alcoholic solution of zinc nitrate with sodium hydroxide under ultrasonic irradiation at room temperature. The graphene and zinc oxide nanocomposites were synthesized in THF and heated in an electric furnace at $700{ }^{\circ} \mathrm{C}$ for $2 \mathrm{~h}$. The graphene- $\mathrm{ZnO}$ nanocomposites were characterized by XRD, SEM and TEM. The catalytic properties of the graphene- $\mathrm{ZnO}$ nanocomposites in the photocatalytic degradation of the organic dyes, methylene blue, methyl orange and rhodamine B in every 5 min period under ultraviolet light at $365 \mathrm{~nm}$ were examined by UV-vis spectroscopy. The photocatalytic effect of the heated graphene- $\mathrm{ZnO}$ nanocomposites was compared with the unheated graphene- $\mathrm{ZnO}$ nanocomposites.
\end{abstract}

Key Words: ZnO nanoparticles, Graphene, Organic dyes, Graphene-ZnO nanocomposites, Photocatalytic degradation.

ᄂ - - - - - - - - - - - - - - - - - - - - - - - - -

\section{INTRODUCTION}

Graphene is a single two-dimensional carbon sheet with the same structure as the individual layers of graphite. This carbon allotrope has attracted a great deal of interest in recent years owing to its excellent electronic, capacitive and mechanical properties, superior chemical stability and high specific surface area $^{1-10}$. Enormous scientific activity has been prompted by its extraordinary electrical, themal and mechanical properties $^{11-14}$. Graphene-based composites are a class of exciting materials with many potential applications ${ }^{11,15}$.

The most interesting application of graphene, catalysis, has been achieved due to the large-scale production of highly conducting graphene sheets ${ }^{16-19}$. Graphene is an alternative to other materials, such as carbon nanotubes(CNTs), activated carbon, fullerene ${ }^{20}$ because of its good conductivity, chemical stability, large surface-to-volume ratio, suitable pore size distribution and good capacitive performance, etc. ${ }^{16}$.

Zinc oxide is an n-type transparent semiconductor material with a wide direct band gap and large exciton binding energy of $3.37 \mathrm{eV}$ and $60 \mathrm{meV}$ at room temperature, respectively. Moreover, it is stable to high energy radiation and wet chemical etching ${ }^{21,22}$. Therefore, $\mathrm{ZnO}$ is becoming a desirable material for many optoelectronic applications ${ }^{21}$, such as solar cells, optical coatings, photo catalyst, electrical devices, antibacterial coatings, active medium in UV semiconductor lasers and in gas sensors ${ }^{23-25}$. Although $\mathrm{ZnO}$ can absorb UV light with a wavelength $\leq 385 \mathrm{~nm}$, it is desirable for higher photo catalytic efficiency and many practical applications that photo catalysts, such as $\mathrm{ZnO}$, absorb both UV and visible light because visible light accounts for $42 \%$ of energy in solar radiation whereas UV light accounts for less than $6 \%$. Therefore, to absorb visible light, the band gap of $\mathrm{ZnO}$ has to be modified or split into several sub-gaps. This can be accomplished by implanting transition metal ions or by doping with nitrogen ${ }^{23,26,27}$.

Heterogeneous photocatalysts can be applied to environmental purification and converting photon energy into chemical energy ${ }^{28-30}$. The rapid recombination of photo-generated charge carries is a major limitation to accomplishing high photocatalytic efficiency. Recombination has faster kinetics than surface redox reactions and decreases the quantum efficiency of photocatalysts significantly. Consequently, it is important to retard the recombination of the charge carriers to improve the photocatalytic efficiency. Many studies have attempted to solve the photocatalys is efficiency problem, i.e., the recombination of charge carriers by coupling the photocatalysts with other materials, such as noble metals ${ }^{28,31,32}$, semiconductors $^{28,33,34}$, carbon nanotubes ${ }^{28,35}$, etc. The developed conjugative structure material hybridized semiconductor as efficient photocatalysts, such as $\mathrm{C}_{60}{ }^{28,36,37}$, polyaniline ${ }^{28,38,39}$ and graphite-like carbon ${ }^{28,40,41}$ has been studied frequently. 
In this study, graphene and $\mathrm{ZnO}$ nanocomposites were synthesized using a physical method not a chemical method. The photocatalytic properties of the heated and unheated graphene- $\mathrm{ZnO}$ nanocomposites in the degradation of three different organic dyes viz., methylene blue (MB), methyl orange $(\mathrm{MO})$ and rhodamine $\mathrm{B}(\mathrm{RhB})$ were tested.

\section{EXPERIMENTAL}

Graphene was purchased from TEnano Tech. $\mathrm{Zn}\left(\mathrm{NO}_{3}\right)_{2}$. $6 \mathrm{H}_{2} \mathrm{O}, \mathrm{NaOH}$, tetrahydrofuran and ethanol were obtained from Samchun Chemicals. The organic dyes (MB, MO and RhB) were supplied by Sigma-Aldrich.

Zinc oxide was treated by ultrasonic irradiation using an ultrasonic generator (UGI1200 Hanil Ultrasonic Co., Ltd.) with a frequency $20 \mathrm{kHz}$ and a nominal power of $750 \mathrm{~W}$. The ultrasonic generator was a horn type system with a horn tip diameter of $13 \mathrm{~mm}$. An electric furnace (Ajeon Heating Industry Co., Ltd.) was used to heat the sample. A UV lamp ( $8 \mathrm{~W}, 365$ nm, 77202 Marne La Valee-cedex 1 France) was used as the ultraviolet light irradiation source.

The surfaces of the unheated graphene, heated graphene, unheated graphene- $\mathrm{ZnO}$ nanocomposites and heated graphene$\mathrm{ZnO}$ nanocomposites were observed by scanning electron microscopy (Hitachi S4700) at an accelerating voltage of 0.5$15 \mathrm{kV}$. The morphology and crystallite size of the samples were examined by transmission electron microscopy (JEOL Ltd, JEM-2010) at an acceleration voltage of $200 \mathrm{kV}$. The structures of the nanomaterials were examined by X-ray diffraction (Bruker, D8 Advance, Germany). UV-VIS spectroscopy of the samples was performed using a UV-VIS spectrometer (Shimazu UV-1601PC).

Synthesis of $\mathrm{ZnO}$ nanoparticles under ultrasonic condition: In a typical experiment, $1.0 \mathrm{M}$ of $\mathrm{Zn}\left(\mathrm{NO}_{3}\right)_{2} \cdot 6 \mathrm{H}_{2} \mathrm{O}$ and $10 \mathrm{M} \mathrm{NaOH}$ were dissolved in $6 \mathrm{~mL}$ of distilled water. Subsequently, $15 \mathrm{~mL}$ of ethanol was added to each solution. After mixing the two solutions in a beaker, the resulting solution was exposed to ultrasonic irradiation for $45 \mathrm{~min}$ at room temperature. At the end of the reaction, the above solution was removed and the white precipitate at the bottom of the beaker was washed with distilled water and ethanol and dried at room temperature ${ }^{42}$.

Synthesis of graphene- $\mathrm{ZnO}$ nanocomposites: In a typical experiment, the prepared graphene nanoparticles and $\mathrm{ZnO}$ nanoparticles were mixed at a mass ratio of $1: 1$. The mixture was dissolved in $10 \mathrm{~mL}$ of tetrahydrofuran with stirring to produce the graphene- $\mathrm{ZnO}$ nanocomposites. The mixture was then dried at room temperature.

Degradation of organic dyes with nanomaterials: The catalytic activity of the unheated and heated graphene- $\mathrm{ZnO}$ nanocomposites was examined using the organic dyes e.g., methylene blue, methyl orange and rodamine B. $10 \mathrm{mg}$ of each nanomaterial was dispersed in $10 \mathrm{~mL}$ of water containing $0.01 \mathrm{mM}$ of each organic dye solution. The mixture solutions were irradiated with ultraviolet light at $365 \mathrm{~nm}$ for $5 \mathrm{~min}$. The organic dyes degraded by each nanomaterial under ultraviolet light were characterized by UV-visible spectroscopy.

\section{RESULTS AND DISCUSSION}

Fig. 1 shows SEM images of the unheated graphene, heated graphene, unheated graphene- $\mathrm{ZnO}$ nanocomposites and heated graphene- $\mathrm{ZnO}$ nanocomposites. The unheated graphene was observed as layer agglomerates with a plate shape [Fig. 1(a)]. Fig. 1(b) shows that the heated graphene nanoparticles had a porous surface with a much smaller size than the unheated graphene nanoparticles. The heated graphene nanoparticles fragmented into smaller particles due to the heat treatment which increased the surface porosity of the heated graphene nanoparticles. The shape of the unheated graphene- $\mathrm{ZnO}$ nanocomposites was a rod type [Fig. 1(c)]. The shape of the graphene- $\mathrm{ZnO}$ nanocomposites changed from a rod type to plate like type and clustered after heat treatment in an electric furnace at $700{ }^{\circ} \mathrm{C}$ for $2 \mathrm{~h}$ [Fig. 1(d)].

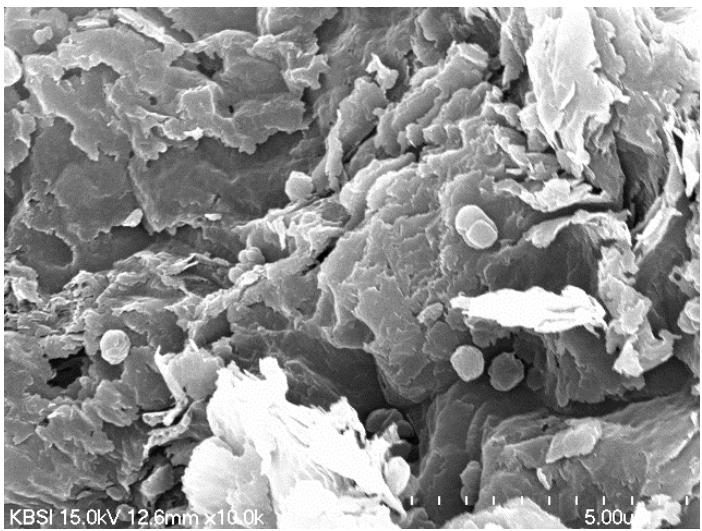

(a)

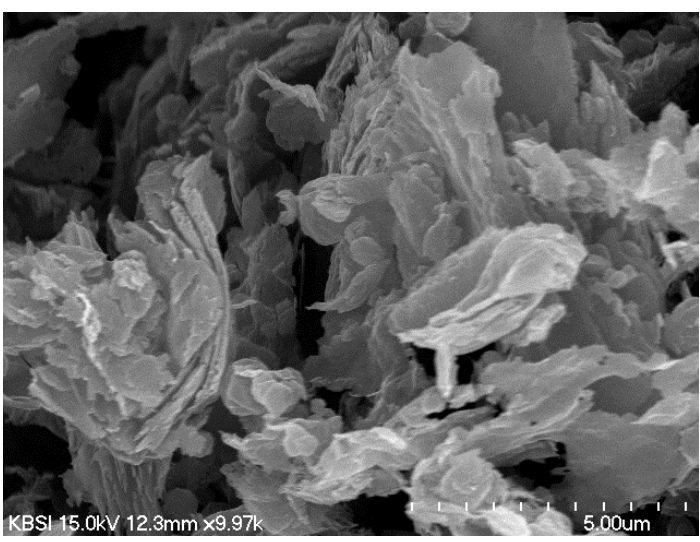

(b)

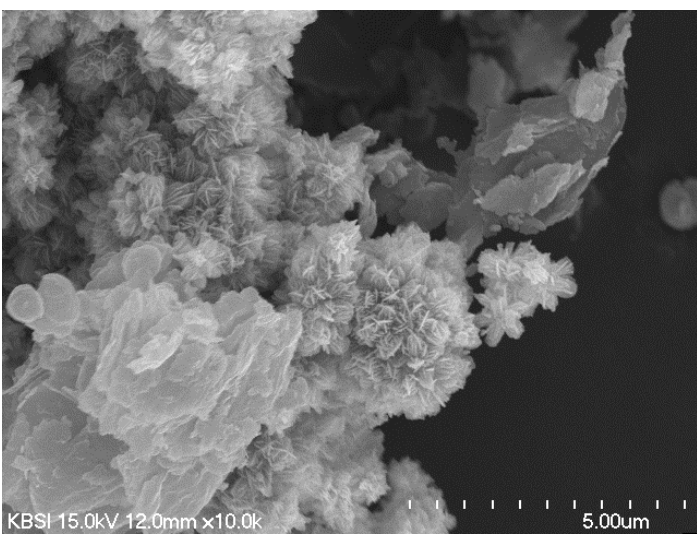

(c) 


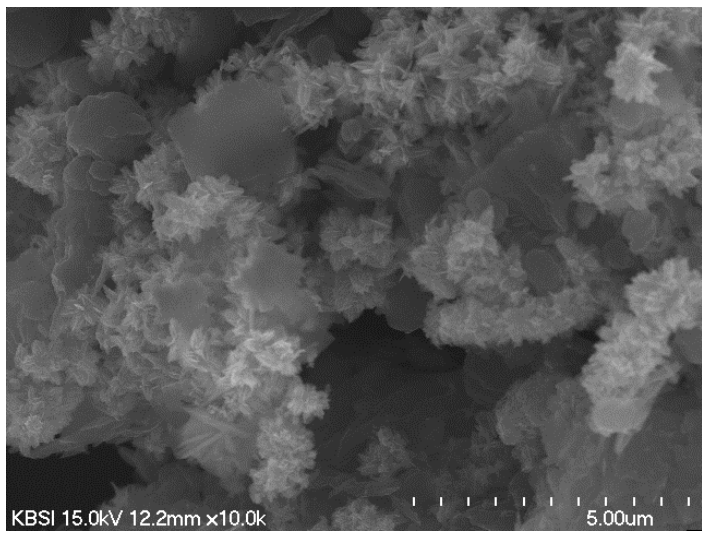

(d)

Fig. 1. SEM images of (a) unheated graphene nanoparticles, (b) heated graphene nanoparticles, (c) unheated graphene- $\mathrm{ZnO}$ nanocomposites and (d) heated graphene- $\mathrm{ZnO}$ nanocomposites

Fig. 2 shows TEM images of the unheated graphene, heated graphene, unheated graphene- $\mathrm{ZnO}$ nanocomposites and heated graphene- $\mathrm{ZnO}$ nanocomposites. The unheated graphene nanoparticles were observed as agglomerates. The size of the heated graphene nanoparticles was smaller than the unheated graphene nanoparticles [Fig. 2(a-b)]. In addition, the heated graphene nanoparticles had a porous surface because of their powder morphology [Fig. 2(b)]. Fig. 2(c) shows that the shape of the unheated graphene- $\mathrm{ZnO}$ nanocomposites was a rod type and the unheated graphene- $\mathrm{ZnO}$ nanocomposites had a large diameter and agglomerated. The shape of graphene- $\mathrm{ZnO}$ nanocomposites changed from rod type to plate like type because they had been heated in an electric furnace at $700{ }^{\circ} \mathrm{C}$ for $2 \mathrm{~h}$. The heated graphene formed a powder with an increased surface area. The diameter of the heated graphene- $\mathrm{ZnO}$ nanocomposites was smaller than that of the unheated graphene- $\mathrm{ZnO}$ nanocomposites due to the decomposition of graphene crystallites.

Fig. 3 shows XRD patterns of the unheated graphene$\mathrm{ZnO}$ nanocomposites and heated graphene- $\mathrm{ZnO}$ nanocomposites. The locations of the peaks for the unheated and heated nanocomposites were similar. In contrast, the intensity of some peaks changed; the heated nanocomposites has more intense peaks than the unheated nanocomposites due to the higher purity after heat treatment at $700{ }^{\circ} \mathrm{C}$ for $2 \mathrm{~h}$. The XRD

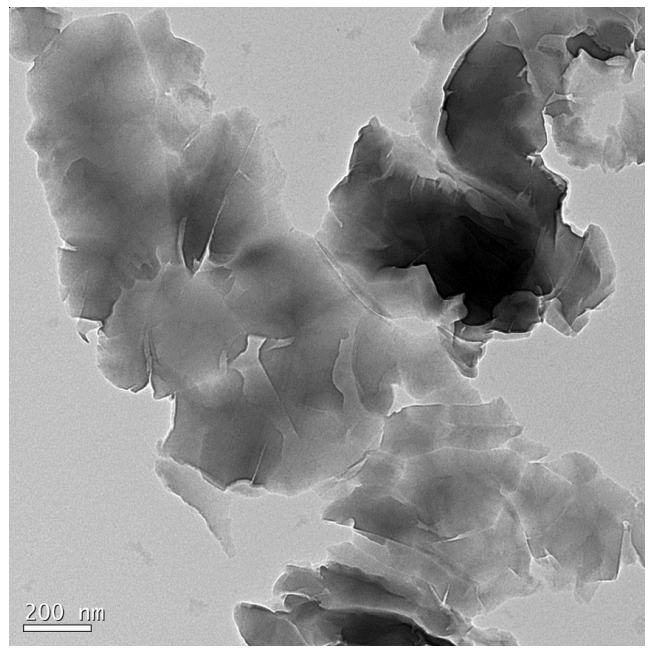

(a)

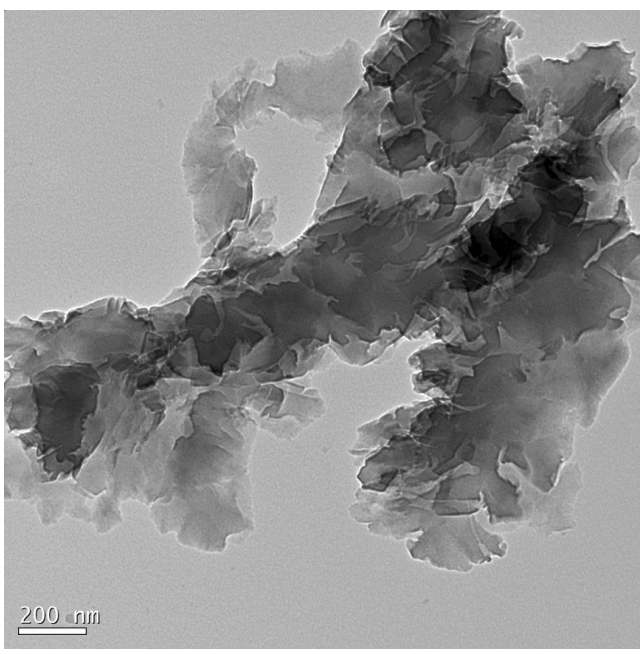

(b)

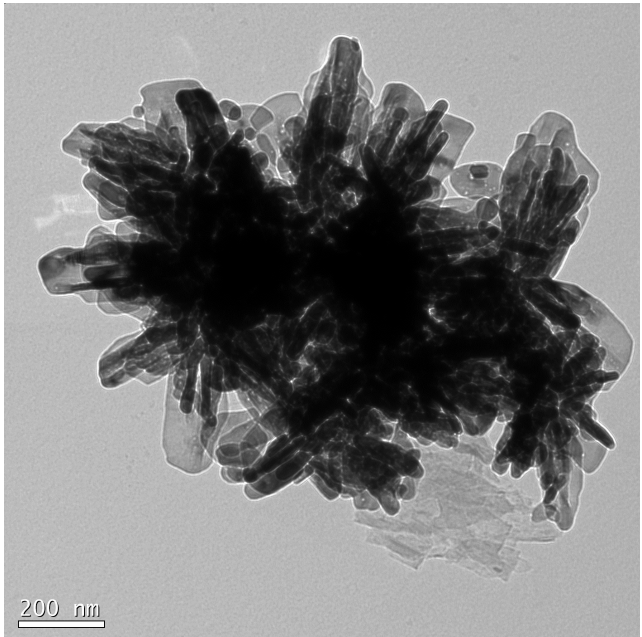

(c)

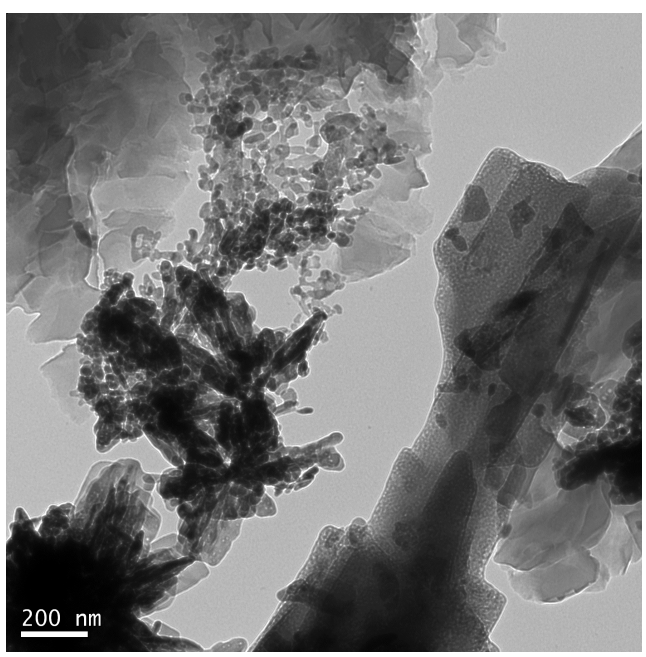

(d)

Fig. 2. TEM images of (a) unheated graphene nanoparticles, (b) heated graphene nanoparticles, (c) unheated graphene- $\mathrm{ZnO}$ nanocomposites and (d) heated graphene- $\mathrm{ZnO}$ nanocomposites

patterns of the unheated and heated graphene- $\mathrm{ZnO}$ nanocomposites showed peaks at approximately $27.28,31.76$, $34.52,36.32,47.66,56.54,62.94,68.10,76.96$ as a $2 \theta$ shown in Fig. 3(a-b). The peaks for the unheated graphene- $\mathrm{ZnO}$ 

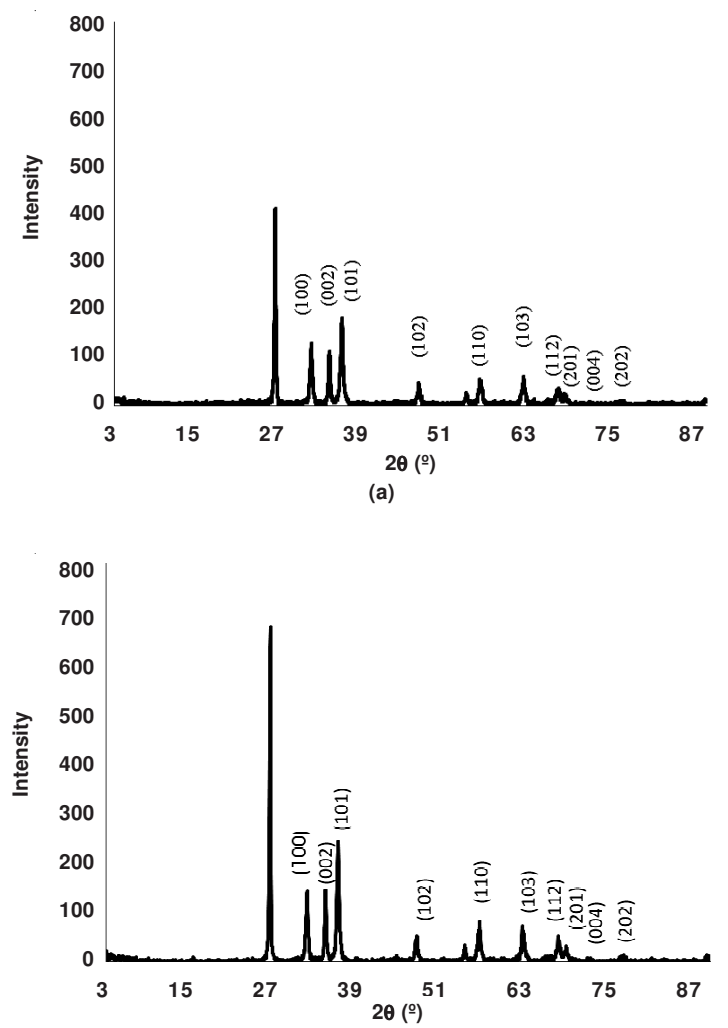

(b)

Fig. 3. XRD patterns of (a) unheated graphene- $\mathrm{ZnO}$ nanocomposites, and (b) heated graphene- $\mathrm{ZnO}$ nanocomposites

nanocomposites showed higher intensity than those of the unheated graphene- $\mathrm{ZnO}$ nanocomposites. The improved crystallinity of the heated graphene- $\mathrm{ZnO}$ nanocomposites than the unheated graphene- $\mathrm{ZnO}$ nanocomposites was attributed to the heating process.

Fig. 4 shows UV-visible spectra of the degraded organic dyes (MB, MO and $\mathrm{RhB}$ ) with the unheated and heated graphene$\mathrm{ZnO}$ nanocomposite under ultra-violet irradiation at $365 \mathrm{~nm}$ for 5 min. Fig. 4 (a) and (b) present the UV-VIS spectra of the degradation of (a) MB, (b) MO, (c) RhB on the unheated and heated graphene- $\mathrm{ZnO}$ nanocomposite, correspondingly. The unheated and heated graphene- $\mathrm{ZnO}$ nanocomposites showed more efficient photocatalytic activity for MB. Among the organic dyes, all the nanocomposites showed the poorest photocatalytic activity for MO. In addition, the heated graphene$\mathrm{ZnO}$ nanocomposite showed better efficiency for the three organic dyes than unheated graphene- $\mathrm{ZnO}$ nanocomposites.

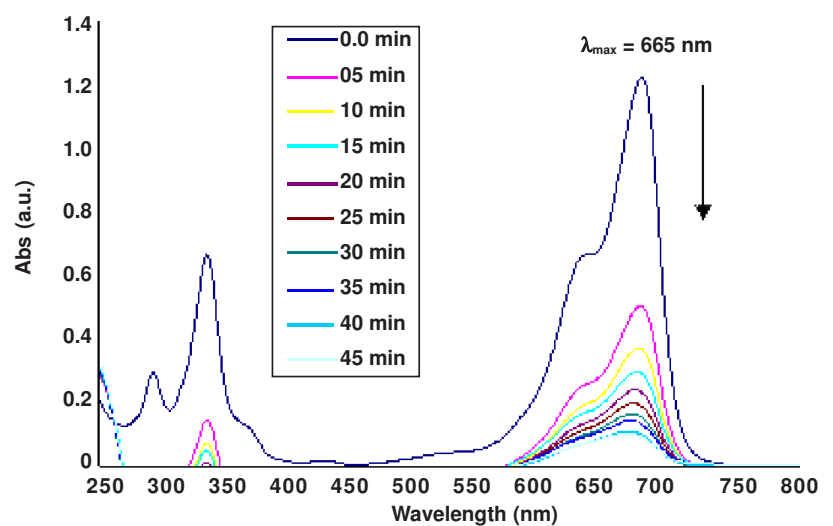

(a)
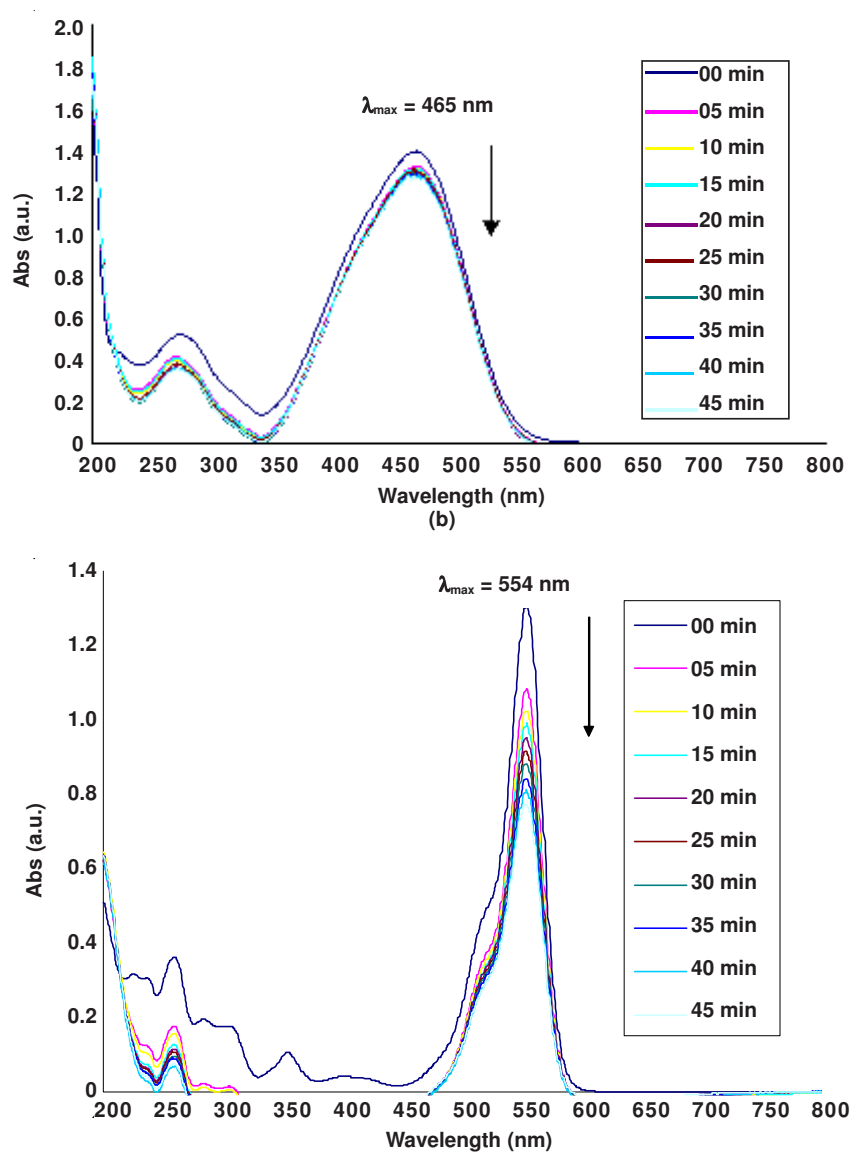

(c)

Fig. 4.1. UV-vis spectra of the degradation in (a) MB, (b) MO, (c) RhB of unheated graphene- $\mathrm{ZnO}$ nanocomposites

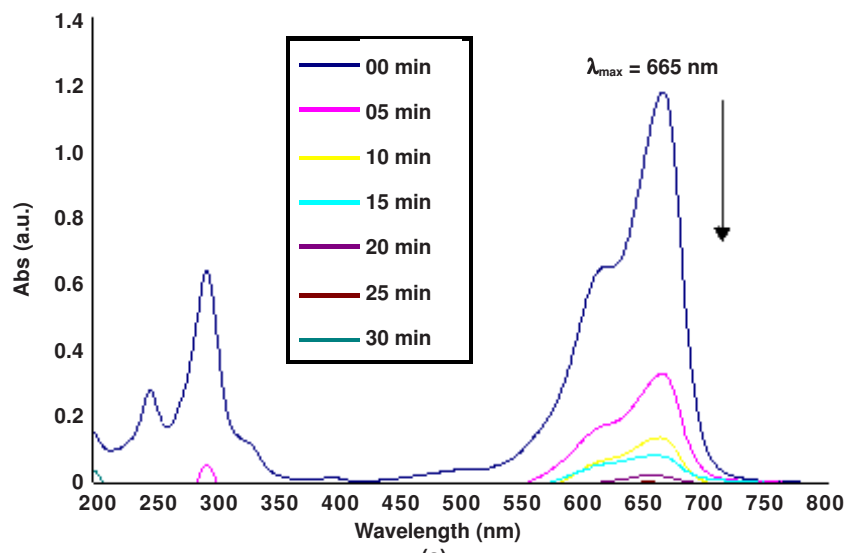

(a)

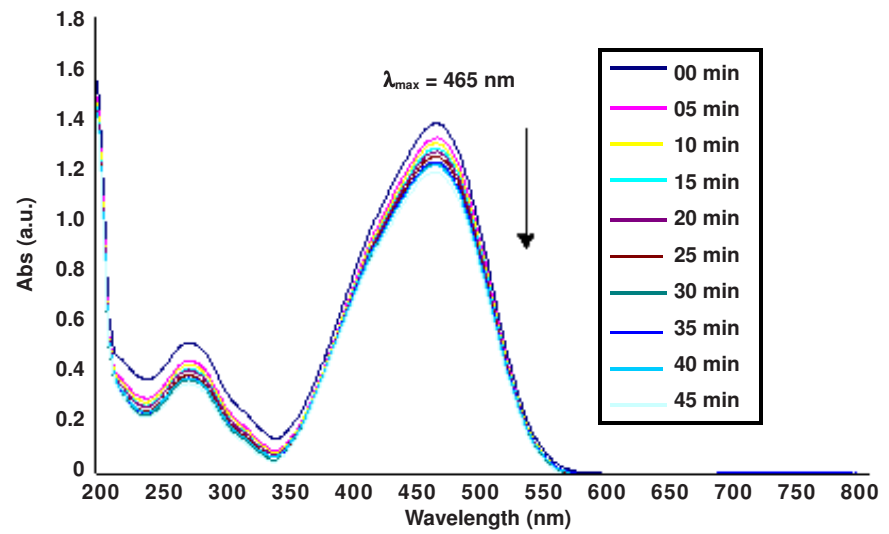

(b) 


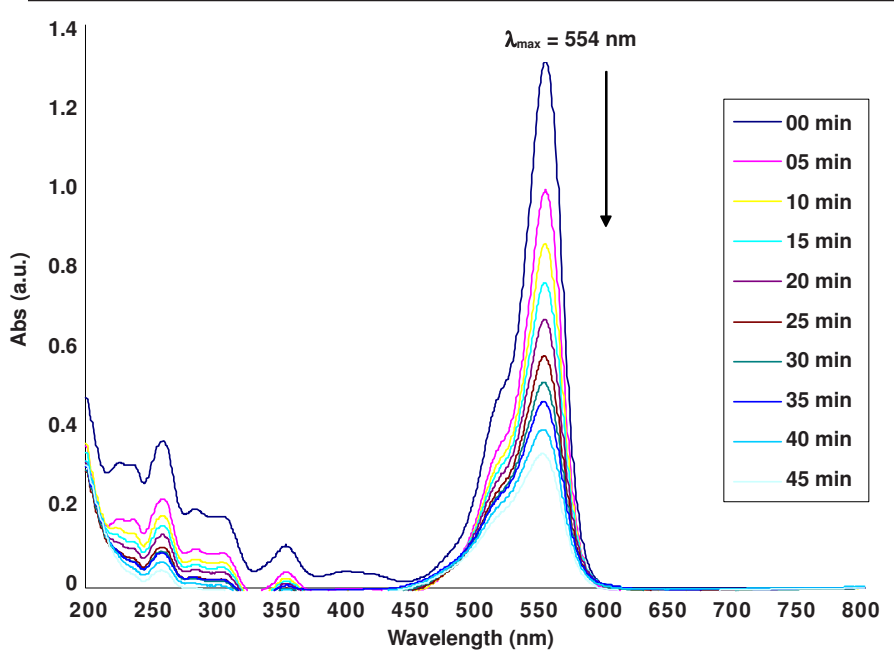

(c)

Fig. 4.2. UV-vis spectra of the degradation in (a) MB, (b) MO, (c) RhB of heated graphene- $\mathrm{ZnO}$ nanocomposites

\section{Conclusion}

Graphene and $\mathrm{ZnO}$ nanocomposites were synthesized using a physical method not a chemical method. The unheated and heated graphene- $\mathrm{ZnO}$ nanocomposites were synthesized as a photocatalyst for the degradation of $\mathrm{MB}, \mathrm{MO}$ and $\mathrm{RhB}$ under ultra-violet irradiation at $365 \mathrm{~nm}$. The unheated and heated graphene nanoparticles showed similar agglomerated morphologies but the heated graphene had smaller particles than unheated graphene. In addition, the heated graphene nanoparticles showed a porous surface with a powdery morphology. The shape of the graphene- $\mathrm{ZnO}$ nanocomposites changed from rod type to plate like type after heating at $700{ }^{\circ} \mathrm{C}$ for $2 \mathrm{~h}$. The heated nanomaterials showed higher surface areas because their nanomaterials had decomposed at high temperature. The heated graphene- $\mathrm{ZnO}$ nanocomposite had better photocatalytic effects in the degradation of the organic dyes under ultraviolet irradiation at $365 \mathrm{~nm}$ than the unheated nanocomposites. Further studies of nanomaterials as photocatalysts for the decontamination of wastewater are currently underway.

\section{ACKNOWLEDGEMENTS}

This study was supported by Sahmyook University funding in Korea and from grants from the Ministry of Knowledge and Economy.

\section{REFERENCES}

1. Ting Lu, Likun Pan, Haibo Li, Guang Zhu, Tian Lv, Xinjuan Liu, Zhuo Sun, Ting Chen and Daniel H.C. Chua, J. Alloys Comp., 509, 5488 (2011).

2. K.S. Novoselov, A.K. Geim, S.V. Morozov, D. Jiang, Y. Zhang, S.V. Dubonos, I.V. Grigorieva and A.A. Firsov, Science, 306, 666 (2004).

3. M.D. Stoller, S. Park, Y. Zhu, J. An and R.S. Ruoff, Nano Lett., 8, 3498 (2008).

4. X.P. Shen, J.L. Wu, S. Bai and H. Zhu, J. Alloys Comp., 506, 136 (2010).

5. S.R.C. Vivekchand, C.S. Rout, K.S. Subrahmanyam, A. Govindaraj and C.N.R. Rao, J. Chem. Sci., 120, 9 (2008).
6. Y. Wang, Z.Q. Shi, Y.F. Ma, C.Y. Wang, M.M. Chen and Y.S. Chen, J. Phys. Chem. C, 113, 13103 (2009).

7. W. Lv, D.M. Tang, Y.B. He, C.H. You, Z.Q. Shi, X.C. Chen, C.M. Chen, P.X. Hou, C. Liu and Q.H. Yang, ACS Nano., 3, 3730 (2009).

8. J. Yan, T. Wei, B. Shao, F.Q. Ma, Z.J. Fan, M.L. Zhang, C. Zheng, Y.C. Shang, W.Z. Qian and F. Wei, Carbon, 48, 1731 (2010).

9. Q. Wu, Y.X. Xu, Z.Y. Yao, A.R. Liu and C.Q. Shi, ACS Nano., 4, 1963 (2010).

10. Y. Chen, X. Zhang, P. Yu and Y. Ma, J. Power Sources, 195, 3031 (2010).

11. Jili Wu, Xioaping Shen, Lei Jiang, Kun Wang and Kangmin Chen, Appl. Surf. Sci., 256, 2826 (2010).

12. K.S. Novoselov, A.K. Geim, S.V. Morozov, D. Jiang, Y. Zhang, S.V. Dubonos, I.V. Grigorieva and A.A. Firsov, Science, 306, 666 (2004).

13. A.K. Geim and K.S. Novoselov, Nat. Mater., 6, 183 (2007).

14. J.C. Meyer, A.K. Geim, M.I. Katsnelson, K.S. Novoselov, T.J. Booth and S. Roth, Nature, 446, 60 (2007).

15. T. Ramanathan, A.A. Abdala, S. Stankovich, D.A. Dikin, M. HerreraAlonso, R.D. Piner, D.H. Adamson, H.C. Schniepp, X. Chen, R.S. Ruoff, S.T. Nguyen, I.A. Aksay, R.K. Prud'homme and L.C. Brinson, Nat. Nanotechnol., 3, 327 (2008).

16. Ting Lu, Yanping Zhang, Haibo Li, Likun Pan, Yinlun Li and Zhuo Sun, Electrochim. Acta, 55, 4170 (2010).

17. M. Choucair, P. Thordarson and J.A. Stride, Nat. Nanotechnol., 4, 30 (2009).

18. R. Hao, W. Qian, L.H. Zhang and Y.L. Hou, Chem. Common., 48, 6576 (2008).

19. V.C. Tung, M.J. Allen, Y. Yang and R.B. Kaner, Nat. Nanotechnol., 3, 101 (2008).

20. S.K. Hong, G. Y. Yu, C.S. Lim and W.B. Ko, Elast. Compos., 45, 206 (2010).

21. U. Alver, W. Zhou, A.B. Belay, R. Krueger, K.O. Davis and N.S. Hickman, Appl. Surf. Sci., 258, 3109 (2012).

22. D.C. Look, Mater. Sci. Eng.B, 80, 383 (2001).

23. Manjula G. Nair, M. Nirmala, K. Rekha and A. Anukaliani, Mater. Lett., 65, 1797 (2011).

24. J.C. Pivin, G. Socol, I. Mihailescu, P. Berthet, F. Singh and M.K. Patel, Thin Solid Films, 517, 916 (2008).

25. K. Sato and H. Katayama-Yoshida, J. Appl. Phys. (Japan), 39, 555 (2000).

26. Igor Djerdj, Zvonko Jaglicic, Denis Arcon and Markus Niederberger, Nanoscale, 2, 1096 (2010).

27. Lin Hsiu-Fen, Liao Shih-Chieh and Hung Sung-Wei, J. Photoch. Photobiol. A, 174, 82 (2005).

28. Tongguang Xu, Liwu Zhang, Hanyun Cheng and Yongfa Zhu.

29. M.R. Hoffmann, S.T. Martin, W. Choi and D.W. Bahnemann, Chem. Rev., 95, 69 (1995).

30. D. Ravelli, D. Dondi, M. Fagnoni and A. Albini, Chem. Soc. Rev., 38, 1999 (2009).

31. T. Hirakawa and P.V. Kamat, J. Am. Chem. Soc., 127, 3928 (2005).

32. V. Subramanian, E.E. Wolf and P.V. Kamat, J. Am. Chem. Soc., 126, 4943 (2004).

33. S.H. Elder, F.M. Cot, Y. Su, S.M. Heald, A.M. Tyryshkin, M.K. Bowman, Y. Gao, A.G. Joly, M.L. Balmer, A.C. Kolwaite, K.A. Magrini and D.M. Blake, J. Am. Chem. Soc., 122, 5138 (2000).

34. T. Tatsuma, S. Saitoh, P. Ngaotrakanwiwat, Y. Ohko and A. Fujishima, Langmuir, 18, 7777 (2002).

35. K. Woan, G. Pyrgiotakis and W. Sigmund, Adv. Mater., 21, 2233 (2009).

36. H.B. Fu, T.G. Xu, S.B. Zhu and Y.F. Zhu, Environ. Sci. Technol., 42, 8064 (2008).

37. S.B. Zhu, T.G. Xu, H.B. Fu, J.C. Zhao and Y.F. Zhu, Environ. Sci. Technol., 41, 6234 (2007).

38. H. Zhang, R.L. Zong and Y.F. Zhu, Phys. Chem. C, 113, 4605 (2009).

39. H. Zhang, R.L. Zong, J.C. Zhao and Y.F. Zhu, Environ. Sci. Technol., 42, 3803 (2008).

40. L.W. Zhang, H.Y. Cheng, R.L. Zong and Y.F. Zhu, J. Phys. Chem. C, 113, 2368 (2009)

41. L.W. Zhang, H.Y. Cheng, R.L. Zong and Y.F. Zhu, Adv. Funct. Mater., 18, 2180 (2008).

42. R.S. Yadav, P. Mishra and A.C. Pandey, Ultrason. Sonochem., 15, 863 (2008). 